\title{
PHÂN TÍCH BIẾN ĐộNG SỬ DỤNG ĐẤT TRONG MỐI QUAN HỆ VỚI YẾU TỐ TỬ NHIÊN HUYỆN THÁI THỤY, TỈNH THÁI BİNH
}

\author{
ThS. PHAM TH!̣ LÀN ${ }^{(1)}$, ThS. LÊ TH!̣ THU HÀ(1) \\ PGS. TS. PHAM VĂN CỰ(2), GS. TS. VÕ CHÍ MỸ $\tilde{Y}^{(3)}$ \\ (1)Trường Đại học Mỏ - Địa chất, (2)Trường Đại học Khoa học Tụ̣ nhiên \\ ${ }^{(3)} H$ ội Trắc địa Bản đồ Việt Nam
}

\section{Tóm tắt:}

Mục tiêu chính của bài báo là xác định biến động sử dụng đất và đánh giá mối quan hệ giữa biến động đó với yếu tố tự nhiên huyện Thái Thụy - Thái Bình. Yếu tố địa mạo, thổ nhưỡng, khoảng cách tới đường bờ và biến động đường bờ được lựa chọn như là biến độc lập trong quan hệ với biến động sử dụng đất khu vực này. Biến động sử dụng đất được phân tích từ ảnh vệ tinh kết hợp với bản đồ địa hình. Phân tích hồi quy logistic đa thức chỉ ra mối quan hệ giữa biến động sử dụng đất với các yếu tố tự nhiên. Kết quả chỉ ra rằng, biến động chủ yếu là biến động đất lúa và hoa màu; biến động đất rừng ngập mặn và biến động đất nuôi trồng thủy sản. Mỗi một cặp biến động khác nhau sẽ có quan hệ đặc trưng với từng điều kiện tự nhiên ở mức độ khác nhau.

\section{Giới thiệu}

Biến động sử dụng đất đóng vai trò chủ yếu đến biến động môi trường và góp phần gây ra biến đổi khí hậu. Việc xác định các nguyên nhân dẫn đến biến đổi sử dụng đất đòi hỏi hiểu cả cách mà con người đưa ra quyết định sử dụng đất và sự tương tác nào giữa các yếu tố tự nhiên và xã hội ảnh hưởng đến việc ra quyết định đó [11]. Điều đó cho thấy rằng các quyết định sử dụng đất được đưa ra và chịu ảnh hưởng bởi các yếu tố tự nhiên và xã hội. Hiện trạng sử dụng đất là kết quả của quan hệ tổng hợp các nhân tố bao gồm cả yếu tố sinh, địa lý và yếu tố kinh tế - xã hội cũng như sự tương tác giữa chúng $[3,8]$. Các nghiên cứu độc lập về mối quan hệ giữa biến động sử dụng đất với các yếu tố tự nhiên cũng được đánh giá bởi một số tác giả. Các kết luận của các tác giả đó không xác định được và khó để tổng quát hóa bởi hạn chế về khu vực nghiên cứu. Tuy nhiên các nghiên cứu đều xác định các yếu tố tự nhiên là điều kiện tất yếu ảnh hưởng đến biến động sử dụng đất
[1,11]. Các nghiên cứu của Pan và các cộng sự, 1999; Chen, 2001; Fu, 2006 đã chứng minh mối quan hệ rất chặt chẽ giữa các yếu tố tự nhiên với biến động sử dụng đất $[5,10]$. Cụ thể như, trong nghiên cứu Jan Kabrda đưa ra một vài giả thuyết sau: (1) có tồn tại mối quan hệ giữa cấu trúc sử dụng đất với các điều kiện tự nhiên, (2) ảnh hưởng các điều kiện tự nhiên dần dần càng mạnh mẽ, (3) ảnh hưởng của điều kiện tự nhiên lên sử dụng đất có thể được dự báo trước, cùng với sự quan tâm về nhu cầu hiệu quả kinh tế và bảo vệ môi trường [6]. Cùng với các giả thuyết đó, một nghiên cứu khác của tác giả ở Slovenia đã chỉ ra sự ảnh hưởng của các điều kiện tự nhiên đến biến động sử dụng đất [2]. Ở đây Jan Kabrda đã tổng quan rằng có một số tác giả đánh giá sự ảnh hưởng của một số yếu tố tự nhiên như thạch quyển, khí hậu và độ cao lên hình thái sử dụng đất, yếu tố ảnh hưởng rõ rệt nhất là độ cao. Nghiên cứu của P. H Temple ở khu vực ven biển Sukumaland đã phân tích mối quan hệ của sử dụng đất với các yếu tố tự nhiên bao gồm: thực vật, thổ nhưỡng, 
tưới tiêu và địa mạo [13]. Nhiều nhà địa lý học chỉ ra rằng sử dụng đất nông nghiệp được xác định chủ yếu bởi các điều kiện tự nhiên. Cụ thể hơn, các nhà nghiên cứu khác cho rằng: với khu vực nông thôn, điều kiện tự nhiên là nhân tố điều kiện của biến đổi sử dụng đất $[5,8,9]$. Huyện Thái Thụy tỉnh Thái Bình là khu vực cảnh quan nông thôn ven biển, sử dụng đất chịu tác động nhiều bởi các yếu tố tự nhiên. Do vậy, bài báo này được đặt ra với các mục tiêu: 1) theo dõi xu hướng biến động sử một số loại hình sử dụng đất chính; 2) đánh giá mối quan hệ giữa các yếu tố tự nhiên với biến động sử dụng đất.

\section{Cơ sở dữ liệu và phương pháp}

\subsection{Khu vực nghiên cứu}

Thái Thụy là huyện đồng bằng ven biển, nằm ở phía Đông Bắc tỉnh Thái Bình, có diện tích tự nhiên 26.584,40 ha, chiếm 16,93\% diện tích tự nhiên của tỉnh, nằm trong toạ độ địa lý từ $20^{\circ} 27^{\prime}$ đến $20^{\circ} 50^{\prime}$ vĩ độ Bắc và từ $106^{\circ} 25^{\prime}$ đến $106^{\circ} 50^{\prime}$ kinh độ Đông.

Thái Thụy là huyện ven biển, thấp dần từ Đông Bắc xuống Tây Nam. Giữa lưu vực có một vùng trũng tập trung với cao độ diễn biến từ $0,3 \mathrm{~m}$ đến $0,5 \mathrm{~m}$. Tại các triền sông Sinh, sông Phong Lẫm, sông Bà Đa rải rác có những vùng đất thấp bám theo 2 bên sông cao độ diễn biến từ $0,4 \mathrm{~m}$ đến $0,7 \mathrm{~m}$. Trên dải đất dọc theo $27 \mathrm{~km}$ từ biển có nhiều vùng đất cao điển hình từ $1,5 \mathrm{~m}$ đến $2 \mathrm{~m}$. Các vùng còn lại địa hình tương đối bằng phẳng có độ cao trung bình từ $0,1 \mathrm{~m}$ đến $1,25 \mathrm{~m}$ rất thuận lợi cho trồng lúa. Đất đai của huyện Thái Thụy rất phong phú và đa dạng, gồm đất cát, đất nhiễm mặn, đất phù sa và đất phèn thuận lợi cho phát triển sản xuất nông nghiệp và nuôi trồng thủy hải sản đa dạng hóa cây trồng vật nuôi.

\subsection{Dữ liệu sử dụng đất}

Dũ̃ liệu sử dụng đất được chiết xuất từ ảnh vệ tinh Landsat 1989, 2001, 2005, 2013 và bản đồ địa hình 1965. Tích hợp thông tin sử dụng đất các thời điểm ta có được dữ liệu biến động qua từng giai đoạn. Dữ liệu này được xác định là biến phụ thuộc. Trong mô hình hồi quy đa thức, biến phụ thuộc có lớn hơn hai trạng thái và ít hơn 20 trạng thái. Trong nghiên cứu này, các trạng thái sẽ được mã hóa từ 0 đến 11 . Trong đó, 0 là đối tượng sử dụng đất không bị biến động, các giá trị 1, 2, 3 ...11 là mã số của từng cặp đối tượng chuyển đổi. Số lượng biến phụ thuộc được xác định tùy thuộc vào biến động chính của từng giai đoạn. Bảng 1 sau đây liệt kê cụ thể các biến phụ thuộc trên từng giai đoạn nghiên cứu. (Xem bảng 1)

\section{Bảng 1: Bảng thống kê các biến phụ thuộc}

\begin{tabular}{|c|c|c|c|c|c|}
\hline \multirow[t]{2}{*}{ Biến động sử dụng đất } & \multicolumn{5}{|c|}{ Khoảng thời gian } \\
\hline & 1965-1989 & 1989-2001 & 2001-2005 & $2005-2010$ & $2010-2013$ \\
\hline Không biến động & $x$ & $x$ & $x$ & $\mathrm{x}$ & $\mathrm{x}$ \\
\hline Đất lúa và hoa màu - đất dân cư & & $x$ & $\mathrm{x}$ & $x$ & \\
\hline Đất lúa và hoa màu - đất trồng cói & $\mathrm{x}$ & & & & \\
\hline Đất lúa và hoa màu - đất nuôi trồng thuỷ sản & & $\mathrm{x}$ & $x$ & $x$ & \\
\hline Đất mặt nước - đất rừng ngập mặn & $x$ & $\mathrm{x}$ & $\mathrm{x}$ & $\mathrm{x}$ & \\
\hline Đất trống - đất nuôi trồng thuỷ sản & & $\mathrm{x}$ & $x$ & $\mathrm{x}$ & \\
\hline Đất rừng ngập mặn - mặt nước & & $\mathrm{x}$ & & & \\
\hline Đất rừng ngập mặn - đất nuôi trồng thuỷ sản & & $x$ & $x$ & $\mathrm{x}$ & \\
\hline Các loại chuyển đổi khác & $\mathrm{x}$ & $x$ & & $x$ & $x$ \\
\hline
\end{tabular}


Nhìn chung, biến động sử dụng đất trong vòng gần 50 năm diễn ra có phức tạp, đa dạng. Trong nghiên cứu này tập trung phân tích biến động 3 đối tượng: biến động đất lúa và hoa màu; biến động rừng ngập mặn; biến động đất nuôi trồng thủy sản

\subsection{Dữ liệu yếu tố tự nhiên}

Các biến độc lập trong nghiên cứu này là các yếu tố tự nhiên bao gồm: địa mạo, thổ nhưỡng, đường bờ và khoảng cách tới đường bờ. (Xem bảng 2)

\subsection{Phương pháp nghiên cứu}

Các mô hình hồi quy lý giải mối quan hệ giữa biến động lớp phủ/sử dụng đất với các chỉ số tự nhiên, kinh tế - xã hội. Mô hình hồi qui logistic đa thức (Multinomial logistic regression) được hiểu là mở rộng của mô hình hồi qui logistic nhị thức với biến phụ thuộc là biến định tính (dữ liệu rời rạc) có nhiều hơn 2 trạng thái (hoặc mức). Ví dụ (không biến động, lúa chuyển thành dân cư, lúa chuyển thành nuôi trồng thủy sản...)

Mô hình hồi qui logistic đa thức có công thức như sau [14]:

$$
\log \left(\frac{p i}{p j}\right)=\alpha_{i j}+\beta_{i 1} x_{1}+\beta_{i 2} x_{2}+\ldots+\varepsilon_{i j}
$$

Giả sử gọi: po là xác suất các đối tượng không biến động

$\mathrm{p}_{1}, \mathrm{p}_{2} \ldots \mathrm{p}_{\mathrm{n}}$ là xác suất chuyển đối của các loại hình sử dụng đất

Khi đó ta có $\mathrm{n}$ phương trình sau:

$$
\begin{aligned}
& \log \left(\frac{p 1}{p 0}\right)=\alpha_{10}+\beta_{11} x_{1}+\beta_{12} x_{2}+\ldots+\varepsilon_{10} \\
& \log \left(\frac{p 2}{p 0}\right)=\alpha_{20}+\beta_{21} x_{1}+\beta_{22} x_{2}+\ldots+\varepsilon_{20} \\
& \log \left(\frac{p n}{p 0}\right)=\alpha_{n 0}+\beta_{n 1} x_{1}+\beta_{n 2} x_{2}+\ldots+\varepsilon_{n 0}
\end{aligned}
$$

Cũng giống như hồi quy logic nhị phân,

\begin{tabular}{|c|c|c|c|}
\hline \multicolumn{2}{|r|}{ Các yếu tố tự nhiên } & Loại biến & Ký hiệu \\
\hline \multirow{4}{*}{ Địa mạo } & Bãi bồi hiện đại & \multirow{4}{*}{ Định tính } & ĐM 1 \\
\hline & Bề mặt tích tụ hỗn hợp sông, biển - đầm lầy & & ĐM 3 \\
\hline & Bề mặt tích tụ biển - gió & & ĐM 4 \\
\hline & Bề mặt tích tụ biển hiện đại & & ĐM 6 \\
\hline \multirow{3}{*}{ Thổ nhưỡng } & Đất cát, cồn cát ven biển & \multirow{3}{*}{ Định tính } & $\mathrm{Cc}$ \\
\hline & Đất mặn ít, trung bình & & $\mathrm{Mi}$ \\
\hline & Đất mặn nhiều & & Mn \\
\hline \multirow{2}{*}{ Biến động đường bờ } & Xói mòn & \multirow{2}{*}{ Nhị phân } & 0 \\
\hline & Bồi tụ & & 1 \\
\hline \multirow{7}{*}{$\begin{array}{l}\text { Khoảng cách tới } \\
\text { đường bờ }\end{array}$} & 0 (biển) & \multirow{7}{*}{ Định tính } & ĐB 0 \\
\hline & $0-800 m$ & & ĐB 1 \\
\hline & $800 m-1600 m$ & & ĐB 2 \\
\hline & $1600 m-2400 m$ & & ĐB 3 \\
\hline & $2400 m-3200 m$ & & ĐB 4 \\
\hline & $3200 m-4000 m$ & & ĐB 5 \\
\hline & $>4000 \mathrm{~m}$ & & ĐB 6 \\
\hline
\end{tabular}
hồi quy logistic đa thức sử dụng nguyên tắc tỉ số xác suất để đánh giá sự phù hợp của

Bảng 2: Dữ liệu các biến độc lập 
mô hình. Tỷ số này xác định dựa vào hai thống kê sau:

$-2 \mathrm{~L} o g\left(\mathrm{~L}_{0}\right)$. Trong đó $\mathrm{L}_{0}$ là giá trị xác suất khi hệ số góc của phương trình có giá trị bằng 0 .

$-2 \log \left(L_{m}\right)$. Trong đó $L_{m}$ là giá trị xác suất của cả mô hình theo từng biến độc lập.

Giá trị xác suất này càng nhỏ, thì mô hình càng phù hợp.

\section{Kết quả}

\subsection{Xu hướng biến động sử dụng đất}

Biến động sử dụng đất huyện Thái Thụy tỉnh Thái Bình được thể hiện trong hình 1 sau đây. Sơ đồ hình 1 sau cho ta thấy rằng đất lúa và hoa màu giảm mạnh trong cả giai đoạn dài 48 năm từ 21694.76 ha xuống 17649.21 ha. Ngược với xu hướng đó là diện tích đất nuôi trồng thủy sản, đất rừng ngập mặn và đất dân cư tăng dần lần lượt 1901834.05 ha, 1304.09 ha và 3110.26 ha. Các loại hình sử dụng đất còn lại tăng giảm không đáng kể. (Xem hình 1)
Sử dụng đất huyện Thái Thụy tỉnh Thái Bình biến động khá phức tạp, song diễn biến được tổng kết với hai giai đoạn chính là 1965 - 1989; 1989 - 2001 và 2001 - 2013. Giai đoạn 1965, những năm trước Đổi Mới (1965 - 1989) sự chuyển đổi sử dụng đất rất nhỏ lẻ và một số đối tượng gần như không biến động. Những năm sau Đổi Mới (1989 2001) sự chuyển đổi sử dụng đất rất mạnh mẽ và đa dạng các hình thức chuyển đổi. Tuy nhiên, sự chuyển đổi tập trung với diện tích lớn bao gồm chuyển đổi đất nuôi trồng thủy sản, chuyển đổi rừng ngập mặn. Sang giai đoạn những năm gần đây (2001 - 2013) sử dụng đất đi vào giai đoạn tương đối ổn định ngoại trừ một số đối tượng biến động với diện tích không nhiều.

\subsection{Phân tích mối quan hệ giữa biến động sử dụng đất với yếu tố tự nhiên}

3.2.1. Biến động đất lúa và hoa màu

Biến động đất lúa và hoa màu thành đất dân cư diễn ra liên tục từ năm 1989 đến năm 2005. Trong giai đoạn 1989 - 2001, hệ số hồi quy nói lên rằng tại khu vực đất cát -

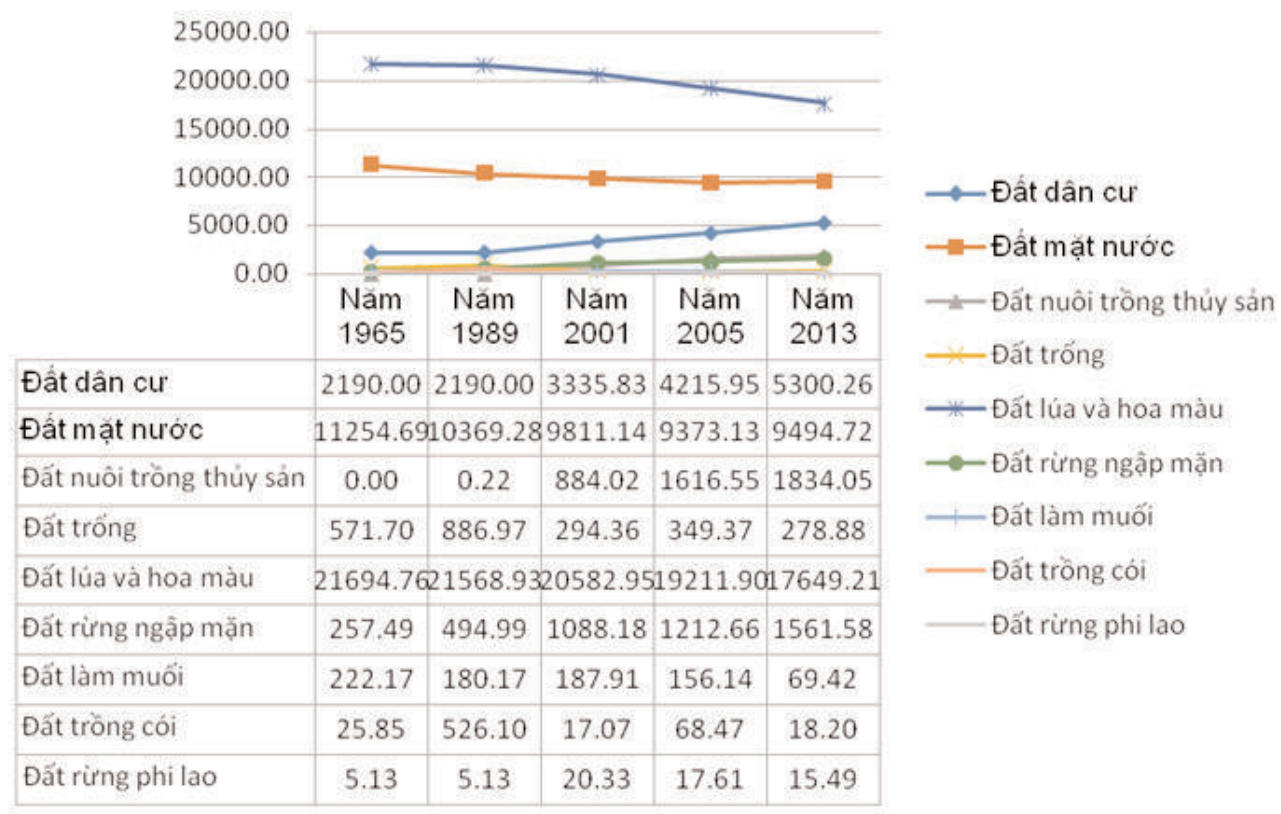

Hình 1: Biểu đồ xu hướng biến đổi sử dụng đất huyện Thái Thụy - Thái Bình 
cồn cát $(\mathrm{C} c=0.53)$, khả năng xảy biến động nay sẽ tăng. Ngược với điều đó, tại khu vực có địa mạo bề mặt tích tu hỗn hợp sông, biển - đầm lầy (ĐM $3=-0.025)$, khả năng chuyển đổi đất lúa và hoa màu thành dân cư sẽ giảm. giai đoạn 2001 - 2005, biến động này xảy ra mạnh với khu vực đất cồn cát $(C c=0.534)$, địa mạo bề mặt tích tụ biển hiện đạin (ĐM $6=0.646)$, bề mặt tích tụ biển - các cồn cát duyên hải (ĐM $8=0.249$ ) và khu vực trong đê. Biến động lúa và hoa màu thành dân cư sẽ giảm với khu vực ngoài đê $(Đ B 0=-0.231)$. Sang đến giai đoạn 2005 2013, xác suất cặp đối tượng biến động này tăng trên khu vực đất phù sa được bồi hàng năm $(\mathrm{Phb}=1.096)$, đất cát - cồn cát $(\mathrm{Cc}=$ 1.1846), ngoại trừ khu vực bề mặt tích tụ biển - gió (ĐM 4 = -1.736).

Biến động lúa thành đất nuôi trồng thủy sản cũng diễn trong giai đoạn tương tự như đất lúa và hoa màu chuyển thành đất dân cư. Giai đoạn 1989 - 2001, hệ số hồi quy chứng minh xác suất chuyển đổi đất lúa và hoa màu thành đất nuôi trồng thủy sản tăng trên khu vực đất mặn nhiều $(\mathrm{Mn}=3.592)$ và bề mặt tích tụ hỗn hợp (ĐM $3=1.841)$. Giai đoạn 2001 - 2005, biến động này chỉ tăng khi ở khu vực ven bờ (ĐB $1=1.111$ ), đất mặn ít $(M i=0.416)$, bề mặt tích tụ hỗn hợp
(ĐM 3 = 2.027) và bề mặt tích tụ biển - gió (ĐM 4 = 2.025). Trong khi đó, giai đoạn 2005 - 2013, hệ số tương quan của đối tượng biến động này với các yếu tố tự nhiên đều âm, ngoại trừ đất mặn ít $(\mathrm{Mi}=2.833)$ và mặn nhiều $(\mathrm{Mn}=0.79)$. Điều này nói lên rằng trên khu vực đất mặn, khả năng chuyển đổi lúa và hoa màu thành đất nuôi trồng thủy sản tăng, còn ở các khu vực có điều kiện tự nhiên khác, sự chuyển đổi này bị hạn chế.

Biến động đất trồng cói thành đất lúa và hoa màu chỉ có ở một giai đoạn duy nhất, giai đoạn đầu sau Đổi Mới (1989 - 2001). Hệ số hồi quy nói nên rằng biến động này có xác suất tăng ở khu vực đất măn ít ( $\mathrm{Mi}=$ 1.124), bề mặt tích tụ hỗn hợp sông, biển đầm lầy $(Đ M 3=1.57)$ và khu vực ngoài bờ ( $\boxminus \mathrm{B} 0=2.331$ ), khu vực đất liền ven bờ ( $\mathrm{B}$ $1=3.251)$.

Tóm lại, biến động đất lúa và hoa màu có quan hệ thuận và nghịch đối với từng yếu tố tự nhiên khác nhau và ở các giai đoạn khác nhau. (Xem bảng 3)

\subsubsection{Biến động rừng ngập mặn}

Số liệu thống kê (bảng 4) chỉ ra rằng đất rừng ngập mặn biến động với sự dịch chuyển về không gian trong suốt giai đoạn

Bảng 3: Hệ số hồi quy giữa biến động đất lúa và hoa màu với các yếu tố tự nhiên chính

\begin{tabular}{|c|c|c|c|c|}
\hline Đối tượng Năm & $1965-1989$ & $1989-2001$ & $2001-2005$ & $2005-2013$ \\
\hline Đất lúa và hoa màu - đất dân cư & & $\begin{aligned} \mathrm{Cc} & =0.53 \\
\text { ĐM3 } & =-0.025\end{aligned}$ & $\begin{aligned} \mathrm{Cc} & =0.534 \\
\text { ĐB0 } & =-0.231 \\
\text { ĐM6 } & =0.646 \\
\text { ĐM8 } & =0.249\end{aligned}$ & $\begin{aligned} \mathrm{Cc} & =1.1846 \\
\text { ĐM4 } & =-1.736 \\
\mathrm{Phb} & =1.096\end{aligned}$ \\
\hline Đất lúa và hoa màu - đất nuôi trồng thuỷ sản & & $\begin{array}{c}\mathrm{Mn}=3.592 \\
Đ M 3=1.841\end{array}$ & $\begin{array}{c}Ð B 1=1.111 \\
\mathrm{Mi}=0.416 \\
Đ M 3=2.027 \\
Đ M 4=2.025\end{array}$ & $\begin{array}{l}M i=2.833 \\
M n=0.79\end{array}$ \\
\hline Đất trồng cói - Đất lúa và hoa màu & & $\begin{array}{c}Ð B 0=2.331 \\
Đ B 1=3.251 \\
\mathrm{Mi}=1.124 \\
Đ M 3=1.57\end{array}$ & & \\
\hline
\end{tabular}


từ 1965 đến 2013. Đồng thời với quá trình rừng ngập mặn bị giảm do chặt phá để trồng cói và nuôi trồng thủy sản là quá trình trồng rừng ngập mặn trên diện tích đất trống và mặt nước.

Đất rừng ngập mặn chuyển đổi thành đất trồng cói chỉ diễn ra từ năm 1965 đến năm 1989. Đây là giai đoạn sau của quá trình khai hoang lập ấp với các công trình quai đê lấn biển theo truyền thống: "Lúa lấn cói, cói lấn vẹt và vẹt lấn biển". Số liệu bảng sau chi biết sự chuyển đổi này tăng ở những khu vực đất mặn ít $(\mathrm{Mi}=16.242)$ và khu vực ven biển (ĐB $1=19.16)$. Ngược lại, trên khu vực đất mặn nhiều $(M n=-0.882)$, bề mặt tích tụ biển - gió ( $(\mathrm{MM} 4=-0.882)$ và bề mặt tích tụ biển hiện đại (ĐM $6=-1.097$ ), khả năng chuyển đất rừng ngập mặn thành đất trồng cói giảm.

Sự chuyển đổi đất rừng ngập mặn thành đất nuôi trồng thủy sản bắt đầu từ những năm đổi mới và tiếp tục cho đến năm 2010. Giai đoạn 1989 - 2001, số liệu hồi quy của biến động này đối với các yếu tố tự nhiên chỉ có giá trị thuận trên khu vực đất mặn nhiều $(\mathrm{Mn}=1.703)$, bề mặt tích tụ hỗn hợp sông, biển - đầm lầy $(\boxminus M 3=1.408)$ và khu vực ven bờ (ĐB $1=0.692$ ). Trên khu vực này, khả năng chuyển đổi đất rừng ngập mặn thành đất nuôi trồng thủy sản tăng. Sang giai đoạn 2001 - 2005, sự chuyển đổi này cũng sẽ tăng tại khu vực mặn nhiều (Mn $=1.034$ ) và ngoài biển ( $\boxminus B \quad 0=1.099)$, song tại khu vực bề mặt tích tụ biển gió (ĐM 4 = -8.563), khả năng chuyển đổi rừng ngập mặn thành đất nuôi trồng thủy sản sẽ giảm.

Mặt nước chuyển thành đất rừng ngập mặn diễn ra liên tục từ năm 1965 đến năm 2013. Giai đoạn đầu (1965 - 1989), biến động này sẽ tăng ở khu vực đất mặn nhiều $(\mathrm{Mn}=0.913)$, đất cát - cồn cát $(\mathrm{Cc}=1.283)$, khu vực gần bờ ( $\boxminus B 1=5.837$ ) và ngoài biển (ĐB $0=9.521)$. Sang giai đoạn (1989 2001), trên khu vực đất mặn nhiều $(\mathrm{Mn}=$ 0.628 ) và ngoài biển ( $\boxminus B$ năng mặt nước chuyển thành rừng ngập mặn tăng. Giai đoạn (2001 - 2005), ngoài khu vực đất mặn ít và khu vực ngoài biến, trên khu vực đất mặn ít $(\mathrm{Mi}=0.089)$, biến động này sẽ tăng. Tuơng tự trên giai đoạn (2005 - 2013) biến động mặt nước thành rừng ngập mặn sẽ tăng tại khu vực đất mặn nhiều và ngoài biển. (Xem bảng 4 )

\subsubsection{Biến động đất nuôi trồng thủy sản \\ Biến động đất nuôi trồng thủy sản rất phong phú với ba cặp chuyển đổi. Các mục}

Bảng 4: Hệ số hồi quy giữa biến động rừng ngập mặn với các yếu tố tự nhiên chính

\begin{tabular}{|c|c|c|c|c|}
\hline Đối tượng Năm & $1965-1989$ & $1989-2001$ & $2001-2005$ & $2005-2013$ \\
\hline Mặt nước - đất rừng ngập mặn & $\begin{aligned} Ð B 0 & =9.521 \\
Ð B 1 & =5.837 \\
\mathrm{Cc} & =1.283 \\
\mathrm{Mn} & =0.913\end{aligned}$ & $\begin{array}{l}Đ B 0=1.46 \\
\mathrm{Mn}=0.628\end{array}$ & $\begin{array}{c}\text { Đ๐ }=1.593 \\
\mathrm{Mi}=0.089 \\
\mathrm{Mn}=0.897 \\
\text { ĐM4 }=-8.832\end{array}$ & $\begin{array}{c}Đ B 0=2.495 \\
M n=10.68\end{array}$ \\
\hline Đất rừng ngập mặn - cói & $\begin{array}{c}\text { ĐB1 }=19.16 \\
\mathrm{Mi}=16.242 \\
\mathrm{Mn}=-0.882 \\
Ð \mathrm{M} 4=-0.882 \\
Ð M 6=-1.097\end{array}$ & & & \\
\hline Đất rừng ngập mặn - thuỷ sản & & $\begin{array}{l}Ð B 1=0.692 \\
\mathrm{Mn}=1.703 \\
Ð \mathrm{M} 3=1.408\end{array}$ & $\begin{array}{c}Ð B 0=1.099 \\
\mathrm{Mn}=1.034 \\
Đ M 4=-8.563\end{array}$ & $\begin{array}{c}Ð B 0=12.094 \\
\text { Đ1 }=10.554 \\
\mathrm{Mn}=15.473\end{array}$ \\
\hline
\end{tabular}


trên đã phân tích hai cặp trừ cặp: Mặt nước - đất nuôi trồng thủy sản.

Bảng hệ số hồi sau (bảng 5) sẽ chỉ ra mối quan hệ của từng cặp biến động với các yếu tố tự nhiên. Ở giai đoạn 1989 - 2001, khả năng chuyển đất mặt nước thành đất nuôi trồng thủy sản trên khu vực đất mặn nhiều $(\mathrm{Mn}=0.974)$ và ngoài biển $(\mathrm{EB} 0=0.169)$. Giai đoạn 2001 - 2005, ngoài khu vực đất mặn, cặp chuyển đổi này còn tăng trên khu vực bãi bồi hiện đại (ĐM $1=2.076)$ và bề mặt tích tụ biển - gió (ĐM $4=11.813)$. Trong khi đó, ở giai đoạn 2005 - 2013, sự chuyển đổi mặt nước thành đất nuôi trồng thủy sản chỉ có mối quan hệ thuận với các yếu tố thổ nhưỡng như đất cát - cồn cát $(\mathrm{Cc}=15.086)$, đất mặn ít $(\mathrm{Mi}=15.42)$ và đất mặn nhiều $(\mathrm{Mn}=16.384)$. (Xem bảng 5$)$

\section{Kết luận}

Biến động sử dụng đất huyện Thái Thụy tỉnh Thái Bình diễn ra mạnh mẽ trong giai đoạn 1965 - 2013. Biến động sử dụng đất là kết quả tương tác của yếu tố tự nhiên và kinh tế - xã hội. Kết quả nghiên cứu chỉ ra rằng: 1) Biến động sử dụng đất đa dạng và phong phú nhưng tập trung chính là biến động đất lúa và hoa màu; biến động đất rừng ngập mặn và biến động đất nuôi trồng thủy sản. 2) Thông qua việc ứng dụng mô hình hồi quy logistic đa thức đã chỉ ra biến động sử dụng đất có mối quan hệ chặt chẽ với các yếu tố tự nhiên bao gồm địa mạo, thổ nhưỡng, khoảng cách tới đường bờ và biến động đường bờ. $O$

\section{Tài liệu tham khảo}

[1]. E.F. Lambin A. Veldkamp (2001), "Predicting land-use change", Agriculture, Ecosystems and Environment, 85, 1 - 6.

[2]. Jan Kabrda (2004), "Influence of natural conditions on land use in the Vysocina region and its changes since the mid- $19^{\text {th }}$ century", Geographica, 2, 15-38.

[3]. David J. Campbell, David P. Lusch, Thomas A. Smucker, Edna E. Wangui (2005), "Multiple Methods in the Study of Driving Forces of Land Use and Land Cover Change: A Case Study of SE Kajiado District, Kenya", Human Ecology, 33 (6), 763-794.

[4]. W.A Clark, P.L.Hosking (1986), Statistical Methods for Geographers (chapter13), John Wiley and Sons, New York.

[5]. Gerald Domon Daiyuan Pan, Sylvie

Bảng 5: Hệ số hồi quy giữa biến động đất nuôi trồng thủy sản với các yếu tố tự nhiên chính

\begin{tabular}{|c|c|c|c|c|}
\hline Đối tượng Năm & $1965-1989$ & $1989-2001$ & 2001-2005 & $2005-2013$ \\
\hline Đất lúa và hoa màu - Đất nuôi trồng thuỷ sản & & $\begin{array}{c}\mathrm{Mn}=3.592 \\
\mathrm{ĐM} 3=1.841\end{array}$ & $\begin{array}{c}Ð B 1=1.111 \\
\mathrm{Mi}=0.416 \\
\text { ĐM1 }=1.133 \\
\text { ĐM4 }=2.025\end{array}$ & $\begin{array}{l}\mathrm{Mi}=0.607 \\
\mathrm{Mn}=0.71\end{array}$ \\
\hline Mặt nước - Đất nuôi trồng thuỷ sản & & $\begin{array}{c}Ð B 0=0.169 \\
M n=0.974\end{array}$ & $\begin{array}{c}\mathrm{Mn}=0.555 \\
Ð \mathrm{M} 1=2.076 \\
\text { ĐM4 }=11.813\end{array}$ & $\begin{aligned} \mathrm{Cc} & =15.086 \\
\mathrm{Mi} & =15.42 \\
\mathrm{Mn} & =16.384\end{aligned}$ \\
\hline Đất rừng ngập mặn - Đất nuôi trồng thuỷ sản & & $\begin{array}{l}Ð B 1=0.692 \\
\mathrm{Mn}=1.703 \\
Đ M 3=1.408\end{array}$ & $\begin{array}{c}Ð B 0=1.099 \\
\mathrm{Mn}=1.034 \\
\text { ĐM }=-8.563\end{array}$ & $\begin{array}{c}Ð B 0=12.094 \\
Ð B 1=10.554 \\
\mathrm{Mn}=15.473\end{array}$ \\
\hline
\end{tabular}


de Blois and Andre Bouchard (1999), "Temporal (1958-1993) and spatial patterns of land use changes in Haut-Saint-Laurent (Quebec, Canada) and their relation to landscape physical attributes", Landscape Ecology, 14 (1), 35 -52.

[6]. Jan Kabrda (2004), "influence of natural conditions on land use in the Vysocina region and its changes since the mid - $19^{\text {th }}$ century", Geographica, ACTA Universitatis Carolinae, 2, 15 -38.

[7]. T.A Domencich, D.A McFadden (1975), Urban Travel Demand: Behavioural Analysis, Amsterdam, North-Holland.

[8]. Rainer Waldhardt and Annette Otte Elke Hietel* (2004), "Analysing land-cover changes in relation to environmental variables in Hesse, Germany", Landscape Ecology, 19, 473-489.

[9]. Lambin E F (1997), "Modelling and monitoring land-cover change processes in tropical regions", Progress in Physical Geography, 21, 375-393.
[10]. Bo-Jie Fu, Qiu-Ju Zhang, Li-Ding Chen, Wen-Wu Zhao, Hubert Gulinck, GuoBin Liu, Qin-Ke Yang, Yong-Guan Zhu (2006), "Temporal change in land use and its relationship to slope degree and soil type in a small catchment on the Loess Plateau of China", Catena, 65 (1), 41-48.

[11]. E. Lambin, \& Geist, H. (2007), "Causes of land-use and land-cover change.", Retrieved from http://www. eoearth.org/view/article/51cbed2 f7896bb431f6905af,

[12]. Eric F. Lambin Suzanne Serneels (2001), "Proximate causes of land-use change in Narok District, Kenya: a spatial statistical model", Agriculture, Ecosystems and Environment, 17.

[13]. P.H. Temple (1965), "Phisical factors influencing land use in coastal Sukumaland", E.Afr.Geogr.Rev, 3, 17-26.

[14]. David W. Hosmer, Jr., Stanley Lemeshow (2000), "Applied Logistic Regression", 2nd Edition, Copyright (c) 2000 John Wiley \& Sons, Inc. O

\section{Summary}

\section{Analysing land use changes in relation to phisical factors in Thai Thuy, Thai Binh}

MSc. Pham Thi Lan, MSc. Le Thi Thu Ha, Hanoi University of Mining and Geology

Assoc. Prof. Dr. Pham Van Cu, Hanoi University of Science

Prof. Dr. Vo Chi My, The Vietnam Association of Geodesy, Cartography and Remote Sensing (VGCR)

This paper aims to detemine the change of land use and assess the relationship between these land use change with natural component of Thai Thuy district, Thai Binh province. Indipendent varians as land scape, soil, distance to coastline and coastline change are used to assess the relation to land use change in the study area. Land use change inperiod of 1965-2013 is extracted from satellite images combined with geographic maps. The characteristic of correlation of each natural component with land use change is defined by application of logistic regression method. The resultshows that the replacement between rice field and annual agricultural or mangrove and aquaculture are the main trend of change. The correlation intensity of each land use change class with each natural component is also presented in this paper. $\mathrm{O}$ 